\title{
ANALISIS STABILITAS TERHADAP OPERASIONAL DESAIN KAPAL IKAN 20 GT DI PALABUHANRATU
}

\author{
STABILITY ANALYSIS FOR 20 GT FISHING VESSEL OPERATIONAL DESIGN \\ IN PALABUHANRATU
}

\author{
Daud S.A. Sianturi dan Sofiyan M. Permana \\ Pusat Pengkajian dan Perekayasaan Teknologi Kelautan dan Perikanan, Balitbang KP, KKP, \\ Jl. Pasir Putih I, Ancol Timur, Jakarta, 14430 \\ e-mail: daud_sianturi@kkp.go.id
}

Diterima tanggal: 7 Mei 2013, diterima setelah perbaikan: 14 November 2013, disetujui tanggal:2 Desember 2013.

\begin{abstract}
ABSTRAK
Stabilitas merupakan salah satu aspek keselamatan dari sebuah desain kapal. Penelitian ini dilakukan di Palabuhanratu menggunakan desain kapal ikan berukuran 20 GT. Pada penelitian ini dilakukan analisis stabilitas pada 5 kondisi pembebanan kapal sehingga menghasilkan kapal yang baik sesuai standarisasi yang telah ditetapkan. Analisis stabilitas yang digunakan untuk mendapatkan lengan penegak GZ dilakukan dengan bantuan perangkat lunak untuk periode oleng menggunakan rumus International Maritime Organization (IMO) dan untuk mengetahui tinggi gelombang menggunakan rumus angkatan laut Jerman. Dari hasil penelitian menunjukkan kelima kondisi pembebanan yang terjadi di kapal memiliki stabilitas yang baik sesuai dengan kriteria yang telah ditetapkan oleh International Maritime Organization (IMO), periode oleng yang terjadi pada kapal berdasarkan kelima kondisi pembebanan berkisar 2,47-3,04 detik dan tinggi gelombang maksimal yang diterima oleh kapal sebesar 1,41 m dengan panjang gelombang sebesar 15,2 m.
\end{abstract}

Kata kunci: stabilitas, 20 GT, Palabuhanratu

\section{ABSTRACT}

Stability is one of the safety aspects of a ship design. This research was carried out at Palabuhanratu by using 20 GT fishing vessel design. This research investigated stability analysis for five ship loading conditions in order to produce a good ship with appropriate standardization which has been established. Stability analysis, which is used to obtain righting lever GZ, is conducted by the use of software, whereas the rolling period is calculated using the International Maritime Organization (IMO) formula and the calculation of wave height is carried out using German's navy formula. The result of research showed that the five loading conditions that occur in ship have good stability in accordance with International Maritime Organization (IMO) criteria. The rolling period of the fifth loading conditions varied between 2,47 seconds and 3,03 seconds, whilst the maximum wave height of the ship is 1,41 m together with wavelength of 15,2 $m$.

Keywords: stability, 20 GT, Palabuhanratu

\section{PENDAHULUAN}

Indonesia adalah negara kepulauan terbesar di dunia dan negara yang sebagian besar wilayahnya terdiri dari laut. Usaha perikanan di laut menjadi tulang punggung perekonomian bagi Indonesia. Untuk menunjang hasil perikanan di laut dibutuhkan kapal ikan yang handal dalam aspek keselamatan para nelayan di atas kapal. Untuk itu diperlukan kapal ikan yang dirancang sesuai dengan persyaratan stabilitas yang berlaku, dalam hal ini mengikuti standar keselamatan yang ditetapkan oleh International Maritime Organization (IMO).

Pembuatan kapal ikan di Indonesia rata-rata mengabaikan aspek stabilitas, yang merupakan aspek yang sangat penting dalam keselamatan 
kapal, seperti dilaporkan pada penelitian Pangalila (2011) yang menyimpulkan bahwa salah satu kapal ikan di pelabuhan Aertembaga Bitung, Sulawesi Utara tidak terlalu stabil karena memiliki sudut oleng yang kecil.

Pada Penelitian ini didesain sebuah kapal ikan dengan ukuran 20 GT untuk wilayah Palabuhanratu, Jawa Barat. Dengan ukuran GT yang lebih kecil dari 30 GT sedangkan posisi Palabuhanratu yang terletak di selatan Pulau Jawa memungkinkan hasil stabilitas kapal ikan harus baik akibat hantaman gelombang laut Samudera Hindia.

Ada beberapa gerakan yang terjadi di kapal (ship motion) yang diakibatkan adanya gaya dari luar maupun dari dalam kapal itu sendiri. Gerakan itu antara lain, gerak lambung atau surging motion (gerakan kapal ke arah depan dan belakang kapal), gerak lenggang atau swaying motion (gerakan kapal ke arah samping), gerak lonjak atau heaving motion (gerakan kapal pada arah tegak), gerak oleng atau rolling motion ( gerak kapal dengan sumbu putar yang membujur kapal dan melalui titik berat kapal), gerak angguk atau pitching motion (gerak kapal dengan sumbu putar yang melintang kapal dan melalui titik berat kapal), dan gerak joli atau yawing motion (gerak rotasi kapal di atas gelombang dengan sumbu putar garis tegak yang kira-kira melalui titik berat kapal) (Soegiono et al.,2006)

Gerakan yang difokuskan pada penelitian ini adalah gerak oleng atau rolling motion, sering juga disebut sebagai stabilitas melintang dari kapal. Gerakan ini sangat beresiko terhadap keselamatan kapal. Jika sebuah kapal tidak memiliki stabilitas yang baik, dapat membuat kapal terbalik atau tenggelam.

Penelitian di bidang stabilitas kapal telah banyak dilakukan antara lain adanya pengaruh nilai $\mathrm{KG}$ (jarak titik berat terhadap dasar kapal secara vertikal) terhadap besarnya muatan yang diangkut kapal, dimana nilai $\mathrm{KG}$ ini berpengaruh pada kestabilan kapal (Marjoni et al., 2010).

Adanya perubahan displacement akibat modifikasi palka ikan pada kapal akan berpengaruh pada stabilitas kapal berupa perubahan nilai GM (Hadi et al., 2012 ). Adapun GM merupakan jarak titik gravitasi ke titik metasentra secara melintang kapal.

Perubahan geometri kapal akan mempengaruhi karakteristik stabilitas kapal dimana semakin besar rasio lebar dan tinggi kapal maka semakin baik stabilitas kapal, semakin besar rasio lambung timbul dan lebar kapal maka semakin baik stabilitas kapal (Paroka et al., 2012)

Pada penelitian ini dilakukan analisa stabilitas statis dan dinamis dari kapal ikan untuk mengetahui nilai GZ sebagai acuan penentuan stabilitas yang baik, penentuan periode oleng dan tinggi gelombang yang mampu diterima kapal. Analisa dilakukan dengan menggunakan bantuan perangkat lunak dan rumus perhitungan.

\section{BAHAN DAN METODE}

Pada penelitian ini model kapal yang dianalisis adalah jenis kapal ikan 20 GT dengan ukuran utama (principal dimensions) terlihat pada Tabel 1.

Tabel 1. Ukuran utama kapal Table 1. Principal dimensions of ship

\begin{tabular}{ll}
\hline Data Kapal & Ukuran \\
\hline LOA (panjang kapal seluruhnya) & $16,8 \mathrm{~m}$ \\
LOD (panjang deck kapal) & $15,2 \mathrm{~m}$ \\
LWL (panjang garis air) & $13,8 \mathrm{~m}$ \\
Cb (koefisien blok) & 0,417 \\
B (lebar kapal) & $3,6 \mathrm{~m}$ \\
H (tinggi kapal) & $1,6 \mathrm{~m}$ \\
T (tinggi sarat air) & $1,3 \mathrm{~m}$ \\
\hline
\end{tabular}

Tahapan awal analisis stabilitas adalah melakukan pembagian 5 kondisi pembebanan yang terjadi di kapal yaitu:

1. Kapal muatan kosong

Beban yang diterima kapal berupa beban berat kapal itu sendiri (kasko, mesin induk, mesin cadangan kelistrikan, baling-baling, poros baling-baling, perlengkapan dan berat kru). Pada kondisi ini kapasitas tangki bahan bakar kiri (0\%), tangki bahan bakar kanan $(0 \%)$, tangki air tawar $(0 \%)$, ruang muat $1(0 \%)$, ruang muat $2(0 \%)$, dan ruang muat $3(0 \%)$.

2. Kapal berangkat menuju fishing ground Pada kondisi ini kapasitas tangki bahan bakar kiri (100\%), tangki bahan bakar kanan $(100 \%)$, tangki air tawar (100\%), ruang muat 
$1(20 \%)$, ruang muat $2(0 \%)$, dan ruang muat $3(30 \%)$.

3. Kapal beroperasi di fishing ground dengan hasil tangkapan $50 \%$.

Pada kondisi ini kapasitas tangki bahan bakar kiri (70\%), tangki bahan bakar kanan (70\%), tangki air tawar (70\%), ruang muat $1(50 \%)$, ruang muat $2(50 \%)$, dan ruang muat $3(50 \%)$.

4. Kapal beroperasi di fishing ground dengan hasil tangkapan $100 \%$.

Pada kondisi ini kapasitas tangki bahan bakar kiri (50\%), tangki bahan bakar kanan (50\%), tangki air tawar $(50 \%)$, ruang muat 1 (100\%), ruang muat $2(100 \%)$, dan ruang muat 3 $(100 \%)$.

5. Kapal meninggalkan fishing ground dengan hasil tangkapan $0 \%$.

Pada kondisi ini kapasitas tangki bahan bakar kiri (30\%), tangki bahan bakar kanan (30\%), tangki air tawar (30\%), ruang muat $1(0 \%)$, ruang muat $2(0 \%)$, dan ruang muat $3(0 \%)$.

Untuk posisi dari tangki bahan bakar kiri, tangki bahan bakar kanan, tangki air tawar, ruang muat 1 , ruang muat 2 , dan ruang muat 3 dapat dilihat pada Gambar 1.

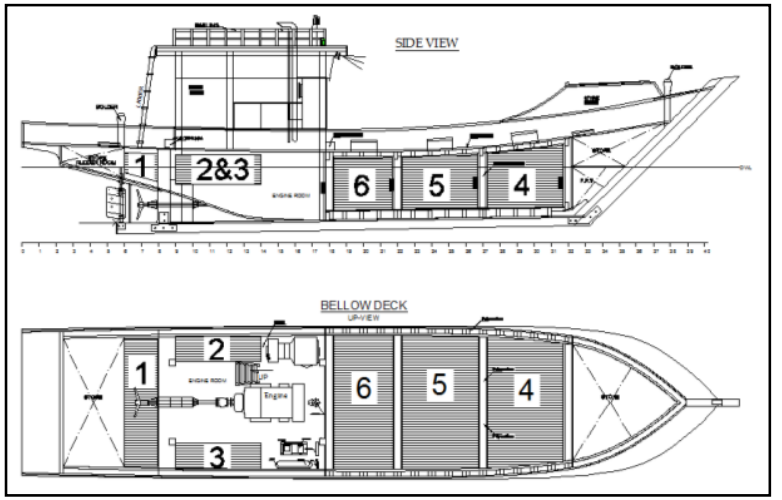

Gambar 1. Posisi pembebanan di kapal Figure 1.Charging position on the ship

Tahapan selanjutnya melakukan analisis stabilitas dengan bantuan perangkat lunak untuk mendapatkan nilai lengan penegak (GZ) dan nilai luasan kurva untuk 5 kondisi yang telah ditetapkan.

Hasil dari analisis stabilitas pada 5 kondisi disesuaikan dengan kriteria umum stabilitas kapal ikan yang dikeluarkan oleh International
Maritime Organization (IMO, 2002), diperlihatkan pada Tabel 2.

Tabel 2. Kriteria umum stabilitas kapal ikan .

Table 2. Common criteria fishing vessel stability

\begin{tabular}{ll}
\hline \multicolumn{1}{c}{ Kriteria } & Nilai Kriteria IMO \\
\hline $0^{0}-30^{\circ}$ & $\geq 3,151 \mathrm{~m} \cdot \mathrm{deg}$ \\
\hline $0^{0}-40^{\circ}$ & $\geq 5,157 \mathrm{~m} \cdot \mathrm{deg}$ \\
\hline $30^{0}-40^{\circ}$ & $\geq 1,719 \mathrm{~m} \cdot \mathrm{deg}$ \\
\hline $\mathrm{GZ}$ max pada sudut $30^{\circ}$ atau lebih & $\geq 0,2 \mathrm{~m}$ \\
\hline sudut GZ & $\geq 25 \mathrm{deg}$ \\
\hline $\mathrm{GM}_{0}$ & $\geq 0,150 \mathrm{~m}$ \\
\hline
\end{tabular}

Pada penelitian ini dilakukan penentuan periode oleng kapal disesuaikan dengan 5 kondisi pembebanan di kapal, serta dilakukan penentuan tinggi gelombang yang mampu dilewati oleh kapal ikan 20 GT ini. Penentuan periode oleng kapal akan menggunakan rumus yang ditetapkan oleh International Maritime Organization (IMO), seperti di bawah ini:

$$
\Phi=\frac{2 \mathrm{CB}}{\sqrt{\mathrm{GM}}}
$$

dimana:

$$
\begin{array}{ll}
\mathrm{C} & =0,373+0,023(\mathrm{~B} / \mathrm{T})-0,043(\mathrm{~L} / 100) \\
\Phi & =\text { Periode oleng }(\text { detik }) \\
\mathrm{B} & =\text { Lebar kapal (meter) } \\
\mathrm{GM} & =\text { Tinggi metasentra (meter) }
\end{array}
$$

Untuk penentuan tinggi gelombang digunakan rumus yang telah ditetapkan oleh angkatan laut Jerman (Biran et al., 2013):

$$
H=\frac{\lambda}{10+0,05 \lambda}
$$

dimana:

$$
\begin{array}{ll}
\mathrm{H} & \text { : Tinggi gelombang (meter) } \\
\lambda & \text { : Panjang gelombang (meter) }
\end{array}
$$

\section{HASIL DAN PEMBAHASAN}

Analisis stabilitas menggunakan model kapal ikan 20 GT dengan ukuran utama sesuai dengan Tabel 1, dimana keadaan kapal bebas mengalami trim dan menggunakan massa jenis air laut sebesar 1,025 tonne $/ \mathrm{m}^{3}$. posisi-posisi distribusi pembebanan tangki air tawar, tangki bahan bakar kiri, tangki bahan bakar kanan, ruang muat 1 , 
ruang muat 2, dan ruang muat 3 dapat dilihat pada Gambar 1 serta persentase kapasitas disesuaikan dengan 5 kondisi yang telah ditetapkan.

Tabel 3. Nilai kriteria stabilitas kapal ikan untuk 5 kondisi yang berbeda

Table 3. Fishing vessel stability criteria value for 5 different conditions

\begin{tabular}{|c|c|c|c|c|c|}
\hline Kriteria & Kondisi 1 & Kondisi 2 & Kondisi 3 & Kondisi 4 & Kondisi 5 \\
\hline $0^{0}-30^{0}$ & 11,193 & 9,323 & 7,752 & 8,622 & 10,624 \\
\hline $0^{0}-40^{0}$ & 19,045 & 15,921 & 13,457 & 15,144 & 18,052 \\
\hline $30^{\circ}-40^{\circ}$ & 7,852 & 6,598 & 5,704 & 6,522 & 7,428 \\
\hline $\mathrm{GZ}_{\max }$ pada sudut $30^{\circ}$ atau lebih & 1,086 & 0,845 & 0,716 & 0,860 & 1 \\
\hline sudut $\mathrm{GZ}_{\max }$ & 70 & 80 & 80 & 80 & 70 \\
\hline $\mathrm{GM}_{0}$ & 1,572 & 1,297 & 1,038 & 1,116 & 1,497 \\
\hline
\end{tabular}

Dari Tabel 3 diperlihatkan nilai untuk berbagai kondisi sesuai dengan kriteria IMO dan dapat dilihat nilai $\mathrm{KG}, \mathrm{GZ}$ dan GM memiliki nilai yang berbeda pada tiap kondisi pembebanan yang terjadi di kapal, akan tetapi memiliki bentuk grafik stabilitas statis yang hampir sama (Gambar 2).

Pada kelima kondisi nilai GZ memiliki nilai (+) positif artinya kapal dapat kembali ke posisi semula setelah terjadinya oleng, sedangkan pada grafik GZ bernilai negatif (kapal tidak memiliki momen pengembali pada saat kapal oleng) terjadi setelah sudut $180^{\circ}$ pada kondisi 1 sampai 5.

Bentuk dari grafik GZ tergantung pada bentuk lambung dan besaran komposisi muatan (Gudmundsson, 2009). Untuk lengan penegak maksimum $\left(\mathrm{GZ}_{\max }\right)$ yang terjadi di kapal memiliki nilai yang berbeda dan terjadi pada sudut tertentu pada kondisi 1 sampai kondisi 5, nilai maksimum GZ yang terjadi adalah stabilitas maksimum yang terjadi di kapal.

Pada kondisi pembebanan 1, 2, 3, 4 dan 5, memiliki nilai MG yang positif dimana titik metacentra (M) berada di atas titik gravity $(\mathrm{G})$, ini memperlihatkan stabilitas yang terjadi pada kapal baik. Nilai KG memiliki besaran yang berbeda pada kondisi 1 sampai 5, hal ini disebabkan perbedaan komposisi pembebanan pada tiap kondisi.

Stabilitas dinamis merupakan karakteristik dari kapal ketika sedang bergerak (khususnya pada saat oleng). Sebuah energi pada kemiringan sebuah kapal pada sudut tertentu diperlukan untuk menetralkan momen stabilitas statis (Gudmundsson, 2009).
Pada Gambar 2 memperlihatkan grafik stabilitas dinamis yang merupakan luasan di bawah grafik lengan penegak (GZ) sampai sudut kemiringan tertentu, pada ujung grafik stabilitas dinamis akan mempunyai garis singgung yang sejajar sumbu absis hal ini terjadi pada saat grafik stabilitas statis menyentuh nol. Bentuk grafik stabilitas dinamis pada kelima kondisi hampir sama, yang membedakan adalah nilai dari grafik stabilitas dinamis pada tiap kondisi, hal ini disebabkan oleh perbedaan berat muatan tiap kondisi. Begitu juga yang telah dilakukan oleh Prasetyo et al. (2012) bahwa stabilitas dinamis dipengaruhi oleh lengan pengembali.

Hasil dari analisis stabilitas tiap kondisi akan disesuaikan dengan kriteria stabilitas menurut IMO yang dapat dilihat pada Tabel 2. Nilai-nilai kelima kondisi telah terpenuhi sesuai kriteria yang ditetapkan IMO, ini membuktikan kapal dapat kembali ke posisi semula setelah terjadi oleng akibat adanya gaya yang terjadi pada kapal.

Dengan menggunakan persamaan 1 maka nilai periode oleng yang dihasilkan pada kondisi kapal muatan kosong sebesar 2,47 detik; untuk kondisi kapal berangkat menuju fishing ground sebesar 2,72 detik; untuk kondisi kapal beroperasi di fishing ground dengan hasil tangkapan 50\% sebesar 3,04 detik; untuk kondisi kapal beroperasi di fishing ground dengan hasil tangkapan $100 \%$ sebesar 2,93 detik; dan untuk kondisi kapal meninggalkan fishing ground dengan hasil tangkapan $100 \%$ sebesar 2,53 detik. 
Kapal muatan kosong

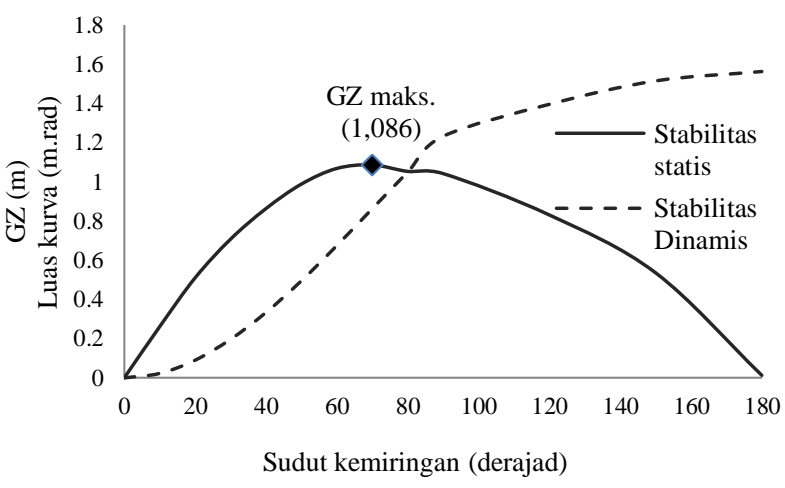

Kapal beroperasi di fishing ground dengan hasil tangkapan $50 \%$

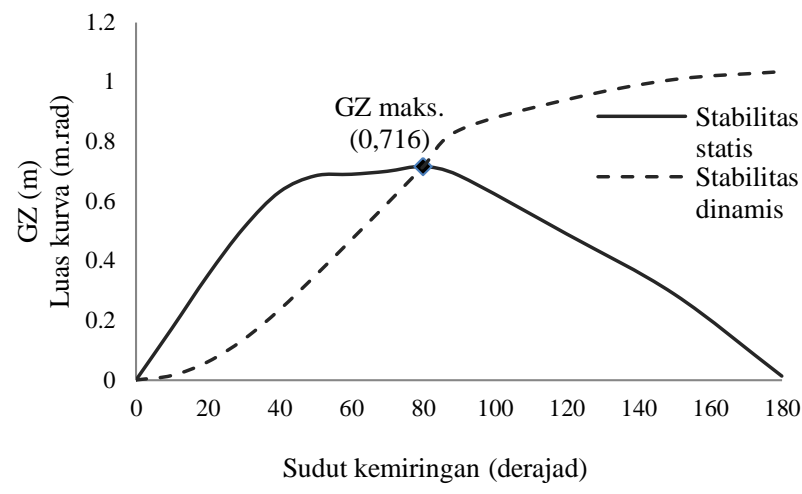

Kapal berangkat menuju fishing ground

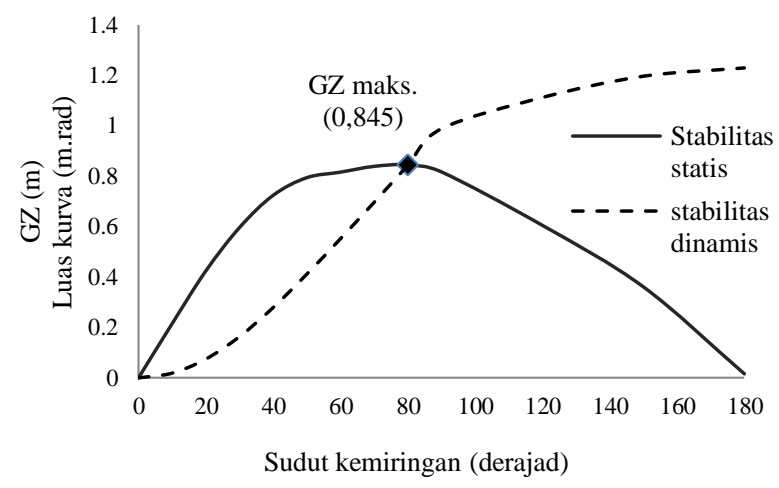

Kapal beroperasi di fishing ground dengan hasil tangkapan $100 \%$

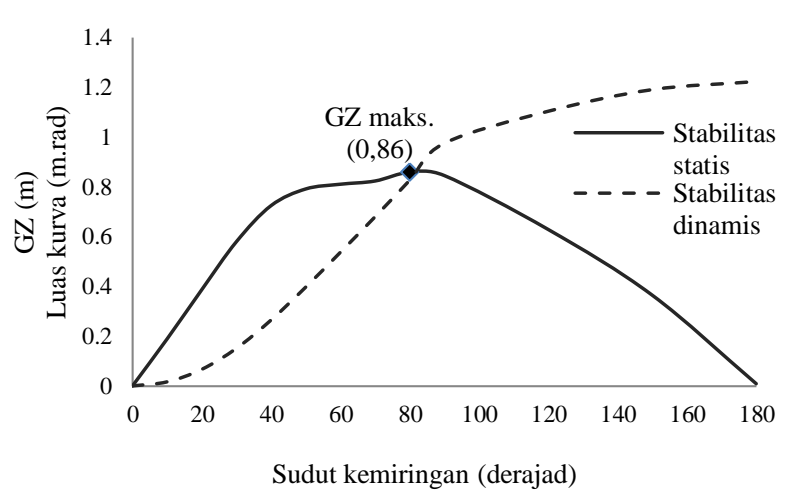

Kapal meninggalkan fishing ground dengan hasil tangkapan $100 \%$

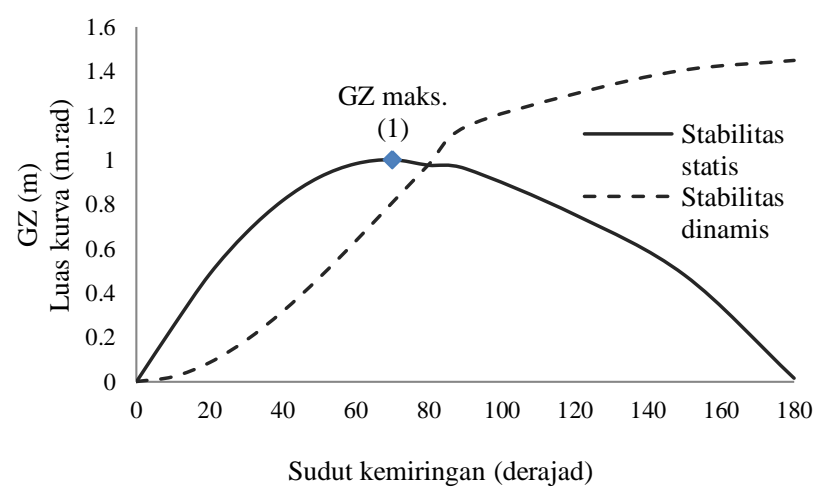

Gambar 2. Kurva stabilitas statis dan dinamis pada berbagai kondisi

Figure 2. Static and dynamic stability curve for different conditions

Menurut Bhattacharyya (1978) standar periode oleng yang terjadi pada kapal ikan adalah 5,5-7,0 detik. Standar ini disesuaikan kenyamanan kru di atas kapal. Nilai kurang dari 5,5 menyebabkan kapal menjadi kaku, menyentak-nyentak dan berimbas pada ketidaknyamanan kru di atas kapal
(Fahrum, 2006), sedangkan nilai melebihi 7,0 akan membahayakan stabilitas kapal, maksudnya adalah, pada saat kapal oleng, waktu momen pengembalian yang lama akan sangat berbahaya bagi kapal ketika terjadi gaya luar susulan secara beruntun dan kapal dapat terbalik. Pada penelitian 
ini periode oleng yang terjadi berkisar 2,47 - 3,04 detik. Bila dibandingkan dengan kriteria Bhattacaryya (1978) maka dapat disimpulkan bahwa kapal ikan tersebut tidak stabil dan dapat mengancam keselamatan kapal. Kondisi ini dapat diatasi dengan penambahan sirip lunas/bilge keel pada bagian bawah kapal.

Untuk mengetahui tinggi gelombang yang mampu dilalui kapal dilakukan perhitungan menggunakan persamaan 2 .

Dengan panjang gelombang yang digunakan sebesar 15,2 m (diambil panjang dari deck kapal) maka dihasilkan tinggi gelombang sebesar 1,41 m, dimana kapal diasumsikan mengalami gelombang sinusoidal. Dari hasil tersebut dapat diartikan bahwa, dengan tinggi gelombang di atas $1,41 \mathrm{~m}$ akan memberikan resiko yang besar terhadap kestabilan kapal.

\section{KESIMPULAN DAN SARAN}

\section{Kesimpulan}

1. Telah dilakukan penelitian persoalan stabilitas kapal ikan 20 GT di Palabuhanratu dimana kondisi stabilitas statis memenuhi kriteria IMO, tetapi karakteristik dinamis (stabilitas rolling) tidak memenuhi kriteria periode rolling yang aman dan nyaman sesuai kriteria Bhattacaryya.

2. Dengan kondisi pembebanan yang berbedabeda menunjukkan nilai $\mathrm{MG}$ yang positif dimana titik metacentra (M) berada di atas titik gravity $(\mathrm{G})$, hal ini memperlihatkan kondisi stabilitas statis yang terjadi pada kapal adalah baik sesuai dengan kriteria IMO.

3. Menurut referensi Bhattacaryya 1978 nilai periode oleng minimal adalah 5 detik sedangkan yang terjadi pada kapal dengan kelima kondisi pembebanan berkisar 2,473,04 detik. Artinya periode rolling/oleng kapal ikan lebih rendah sekitar $40 \%$ dari persyaratan minimal sehingga kapal tersebut tidak nyaman. Untuk mengatasinya, antara lain, dapat dilakukan dengan perubahan desain/bentuk kapal dan pemasangan lunas bilga. Penelitian lebih lanjut sangat direkomendasikan.

4. Tinggi gelombang maksimal yang diterima oleh kapal sebesar 1,41 m dengan panjang gelombang sebesar 15,2 $\mathrm{m}$ sehingga dapat memperhitungkan resiko yang diterima kapal akibat gelombang tinggi.

\section{Saran}

Dengan penambahan sirip lunas/bilge keel pada bagian bawah kapal maka diperlukan penelitian lanjutan untuk mengetahui model maupun lokasi penempatan sirip lunas secara optimum sehingga nilai periode oleng sesuai dengan kriteria yang diharapkan.

\section{UCAPAN TERIMA KASIH}

Penulis menyampaikan terima kasih kepada Pusat Pengkajian dan Perekayasaan Teknologi Kelautan dan Perikanan atas dana APBN yang digunakan untuk kegiatan riset kajian rancangan kapal ikan 20 GT .

\section{DAFTAR PUSTAKA}

Biran, A.B., \& Pulido, R.L. (2013). Ship hydrostatics and stability ( $2^{\text {nd }}$ ed.). Oxford: Elsevier.

Fahrum, S.A. (2006). Kajian stabilitas dan keselamatan operasional kapal pole and line pada gelombang beam seas. Unpublished doctoral dissertation. Institut Pertanian Bogor, Indonesia.

Gudmundsson, A. (2009). Safety practicies related to small fishing vessel stability. Roma: FAO Fisheries and Aquaculture Technical Paper.

Hadi, E.S., Manik P., \& Juwanto. (2012). Analisa performance kapal ikan tradisional KM. Rizky Mina Abadi dengan adanya modifikasi palka ikan berinsulasi polyuretahne. Jurnal Kapal, 9 (2), 68-73.

International Maritime Organization. (2002). Code on intact stability for all types of ships covered by IMO Instruments. London: IMO Publication.

Marjoni, Iskandae, B.H., \& Imron M. (2010). Stabilitas statis dan dinamis kapal purse seine di Pelabuhan Perikanan Pantai Lampulo Kota Banda Aceh Nanggroe Aceh Darussalam. Jurnal Marine Fisheries, 1 (2), 113 - 122.

Pangalila, F.P.T. (2011). Stabilitas statis kapal pole and line KM Aldeis di Pelabuhan 
Perikanan Aertembaga Bitung Sulawesi Utara. Jurnal Perikanan dan Kelautan Tropis, 7 (1), 21-26.

Paroka, D., Asri, S., Misliah, Sarna, M.A., \& Haswar. (2012). Pengaruh karakteristik geometri terhadap stabilitas kapal. SENTA Inovasi Teknologi Kelautan. Surabaya, Indonesia. Hal 1-8.

Prasetyo, N.A., Murtedjo, M., \& Djatmiko, E.B. (2012). Analisa stabilitas dinamis ecogreen barge pada operasi towing. Jurnal Teknik POMITS, 1(1), 1-6
Santoso, I.G.M., \& Sudjono, J.S. (1983). Teori bangunan kapal 2. Jakarta: Departemen Pendidikan dan Kebudayaan.

Soegiono, Sastradiwongso, T., Sasongko, B., Andrianto, P., Soeweify, Moernadi, E., ... Sastrowiyono, K. (2006). Kamus teknik perkapalan $\left(4^{\text {th }}\right.$ ed.). Surabaya: Airlangga University Press. 